\title{
Applying fuzzy delphi and best-worst method for identifying and prioritizing key factors affecting on university-industry collaboration
}

\author{
Alireza Mosayebia ${ }^{\mathrm{a}}$, Shahryar Ghorbani ${ }^{\mathrm{b}}$ and Behzad Masoomi ${ }^{\mathrm{c}^{*}}$ \\ ${ }^{a}$ Ph.D of Decision Making and Policy Making, Lecturer at University of Mazandaran, Faculty of Economics \& Administrative Science, Babolsar, Iran \\ ${ }^{b}$ PhD Student in Management and Business Administration Programme, Graduate School of Social Sciences, Istanbul Gedik University, Turkey \\ ${ }^{c}$ PhD student in Operation Management, Department of Management, Islamic Azad University, Firoozkooh Branch, Tehran, Iran

\begin{tabular}{l}
\hline C H R O N I C L E \\
\hline Article history: \\
Received June 15, 2019 \\
Received in revised format: \\
June 20, 2019 \\
Accepted July 27, 2019 \\
Available online \\
July 27, 2019 \\
\hline Keywords: \\
University- Industry collaboration \\
Technology \\
Incubator \\
University affiliated research \\
institutes
\end{tabular}

\begin{abstract}
A B S T R A C T
The collaboration between the universities and industries is currently in the focus of attention globally. Governments, universities, and industries are interested in good and effective collaboration, which would be beneficial for all parties. To foster University-Industry Collaboration, and to help transfer the knowledge and technology between these two parties, academics, politicians and companies are paying attention to science and technology policies more than ever. In this study, the factors affecting the improvement of University-Industry Collaboration are identified and prioritized. In the first step, 20 factors are identified and 12 factors are selected using the Fuzzy Delphi method. Then, using the BWM method, prioritizing the extracted factors is determined for industry sponsorship of the university research. Finally, based on the results, the discussion is conducted and six major strategies are presented to improve this relationship.
\end{abstract}

\section{Introduction}

The cooperation between universities and businesses is presently within the focus of attention globally. Governments, universities, and businesses have an interest in smart and effective collaboration, which might be useful for all parties. To foster university-industry cooperation, and therefore the data and technology transfer between these 2 parties, academics, politicians and corporations have been cooperating to promote their relationships. For coming up with and evaluating the policies, it is vital to outline and use correct indicators. Though many governments and agencies are regularly looking for ways to facilitate the interactions between businesses and universities, hoping that they would increase the productive processes. They also look for correct indicators to build university-industry collaboration to form political selections at the national level (Seppo \& Lilles, 2014). In addition, universities and corporations will use these indicators in evaluating the collaboration results. Governments square measure actively promote the formation and development of U-I networking by coming up with and implementing innovation policies consequently (Perkmann et al., 2013; Etzkowitz et al., 2000; Park \& Leydesdorff, 2010; Giuliani \& Arza, 2009; Tuunainen \& Knuuttila, 2009; Charles, 2003). Nevertheless, our understanding of the underlying mechanisms of U-I interaction remains restricted (Steinmo \& adventurer, 2016; Villani et al., 2016).

\footnotetext{
* Corresponding author. Tel.: +989112267648

E-mail address: masoomibehzad4@gmail.com (B. Masoomi)

(C) 2020 by the authors; licensee Growing Science, Canada.

doi: $10.5267 /$ j.ds1.2019.7.001
} 
Without adequate complementary data concerning business and marketplace, university researchers could also be unable to acknowledge or exploit the opportunities in their technological discoveries (Franklin et al., 2001; Rasmussen \& Borch, 2010; Venkataraman, 1997; Vohora et al., 2004). Within the context of developing countries, university researchers' access to industrial data could also be even crucial, as universities typically have to be compelled to undertake additional development or problemsolving work on the far side science lab innovations because of the poor sponge like capacities of exploitation partner companies (Eun et al., 2006). There are several methods for transferring technology or data from university to business (U-I), which is tutorial entrepreneurs' learning from business, i.e. data transfer from business to college (I-U), is an imperative issue. The reverse data flows (IU) also are a rife modality as tutorial entrepreneurs learn from business practitioners to get new ideas with higher potential to be commercialized (Baba et al., 2009; D'Este \& Patel, 2007; Siegel et al., 2003). According to Gardner et al. (2010), the data transfer activities have to demonstrate the profit to society from advances in knowledge, to make sure comfortable returns on investment, to produce benchmarks for comparison across the business, to push competition within the world marketplace, and to support future appeals for funding. The businesses have an interest within the returns on investment, which is additionally vital to think about the case of university-industry cooperation activities. The data transfer between universities and business is conducted through varied channels and practices. Therefore, in analyzing and evaluating the cooperation between academe and business, it is necessary to think about the range of connections.

In general University-industry (U-I) collaboration is thought of a relevant economic driver as universities specialize data which are expected to contribute to the economic development of nations or regions. Data and technology transfer between universities and businesses are anticipated to spur innovation, as this sort of collaboration combines not solely heterogeneous collaborates, but heterogeneous the data. Because of the lack of uniformity, partners at the same time face the necessity to cross-different boundaries whereby, managing their boundaries is that the central challenge for interorganizational collaboration (Tsasis, 2009). In general, University-industry (U-I) collaboration is nowadays considered as a relevant economic driver as universities specialized knowledge that is expected to contribute to the economic development of countries or regions. Knowledge and technology transfer between academia and industry is expected to spur innovation, as this kind of collaboration combines not only heterogeneous collaborates, but also more importantly, heterogeneous knowledge. Due to this heterogeneity, partners concurrently face the need to cross-different boundaries whereby, managing their boundaries is the central challenge for inter-organizational collaboration (Tsasis, 2009). Therefore, the boundary spanning and relevant social processes may open important aspects of U-I collaboration.

In Iran, cooperation between industry and the university has always been poor and has not provided a suitable platform, both for the university and for the industry. Implementation of this cooperation has always experienced some fundamental obstacles. Therefore, the present study is accomplished to identify and prioritize the affective factors for the improvement of cooperation between industry and university. Accordingly, the purpose of the research is to first find the most important factors in the subject literature and research background and then the prioritization of improvement indicators is performed using Fuzzy Delphi and BWM. The reason for using these two models in the research is due to its high measurability and reliability compared with other approaches.

This paper attempts to achieve the goal mentioned above in two parts. In the first section of the study, critical factors for identifying the effective indicators in cooperation between industry and university at the University of Tehran one level are searched through the literature review tool and the background of the research. In the second part of the study, these indicators are screened and localized with a fuzzy Delphi model and then evaluated and prioritized using the BWM technique. 


\section{University- Industry collaboration}

Since their foundation, the role of universities in society has modified over time. At first, the universities were aside from society and their role was to preserve the culture and data for the society (Brockliss, 2000; Etzkowitz et al., 2001). Over time, the interaction with establishments outside universities has augmented significantly. The linkages between universities and enterprises have modified to forms and within the intensity of interaction. The oldest mission of university was to provide some teaching to supply ball-hawking and skilled specialists for society. Within the nineteenth century, the universities began to focus on analysis (Brockliss, 2000). The analysis produces and disseminates some results through publications. According to Etzkowitz (2001) the colleges of these days need to notice the acceptable balance between teaching, basic and applied analysis, and entrepreneurship.

Santoro (2000) and Santoro, Chakrabarti (2002) distinguish four forms of university-industry relationships:

- Research support, that embodies monetary and instrumentation contributions created to universities by trade. These contributions may be unrestricted gifts of endowment trust funds that the university uses to upgrade laboratories, offer fellowships to students, or offer capital for promising new outcomes. Nowadays, the support for university analysis is additional targeted and infrequently tied to specific analysis outcomes, which, in return, offer data and new technologies to trade.

- Cooperative analysis includes contract analysis with individual investigators, consulting by faculty, and bound cluster arrangements specifically for addressing immediate trade issues. Within the case of individual investigators or a practice there is typically just one academician concerned named World Health Organization which is functioning with one firm on a targeted scientific research.

- Knowledge transfer encompasses extremely interactive activities that embody on-going formal and informal personal interactions, cooperative education, program development, and personnel exchanges.

- Technology transfer additionally involves extremely interactive activities. Compared to data transfer the main focus here is on addressing immediate and additional specific trade problems. In technology transfer, the university-driven analysis and trade experience create complementary contributions into commercial technologies required by market. Typically, the university provides basic and technical data at the side of technology patent of licensing services. Trade members offer data in an exceedingly specific applied space at the side of a transparent downside statement associated with market demand. Technology transfer takes place through technological consulting arrangements, the firm's use of university's extension services, collectively in hand or operated ventures .

Collaboration between business practitioners and tutorial researchers has been conceptualized as a higher-level method that encompasses cooperation and coordination (Bedwell et al., 2012). U-I collaboration has been characterized by "cultural divide" between partners in terms of goals, views, motives and routines; so, such collaboration is very many-sided. The decision-making processes is normally difficult (Bäck \& Kohtamäki, 2015), and individual factors have an effect on it. Amabile et al. (2001) attributed 3 necessary options for the collaboration between tutorial researchers and business practitioners: 1) it involves those that area unit members of various professions (academia and business); 2) it's a collaboration between people or groups, not between organizations; and 3) the collaborators are not all members of a similar organization. The excellence of people and groups versus organizations may be relevant purpose of departure during this study, because the abstract approach focuses on people and groups. Organizations produce the context for the collaboration, whereas motivation and maturity for that depends rather on the particular characteristics of acting people and groups than on the overall organizational processes. 
During the past few years, analysis has been conducted on collaboration between trade and therefore the university :

Research has shown that there are a unit bound characteristics of a corporation that influence its ability to utilize outwardly generated knowledge domain, and therefore the data are transferred from universities (Agrawal 2001). The amount of assimilatory capability depends on previous connected data and knowledge (Cohen \& Levinthal, 1990). Barnes et al. (2002) outlined in their analysis the complementary experience or strengths, history as collaboration partners within the past, shared vision or strategic importance, complementary aims, and cooperative expertise usually as necessary firm characteristics, that area unit sensible stipulation for thriving cooperation. The standard of workers may be thought-about as firm capabilities. The matter here is that it is exhausting to have it objectively. The indications of firm capability may be, as an example, quality certificates (ISO certificates), variety of previous comes with universities, membership in some analysis cluster or cooperative network, variety of scientists, education of workers, and therefore the involvement of workers within the activities of university (e.g. guest lecturers in university).

According to Perkmann et al. (2011) Patent applications or patents granted may be used as measures of the technological output of university-industry outcomes. Also, some university-industry alliances area unit supported specific 'open science' rules that stipulate that each one data generated ought to flow into the general public domain with no restrictions.

The number of publications in peer-reviewed journals is employed in academic as a serious performance metric. The amount of joint publications of university and trade scientists may be a terribly specific indicators of university-industry collaboration (Langford et al., 2006). Tijssen et al. (2009) used joint analysis publications that area unit co-produced by R\&D workers from non-public sector organizations and universities for evaluating university-industry analysis cooperation. The joint analysis publications are specialized in longer-term views whereas applied analysis in a short- or medium-term development focus on area unit typically not disseminated within the peer-reviewed literature. Patents or alternative type, which frequently are also confidential. The co-authored publications area unit thought-about to be an honest indicator of diffusion of information and skills, and informal network between universities and firms. The indicator is additionally quantitative, available, and straightforward to gather. However, it is necessary to know that this indicator should not be used alone for outlining university-industry cooperation as there are unit several cases wherever no co-authored papers area unit revealed (Lundberg 2006).

Perkmann et al. (2011) believe that intensity of the collaboration is associated with the coaching and learning opportunities between universities and businesses. From analysis, it seems that there are completely different methods for creating functions (Iqbal et al. 2011). Workshops, seminars and conferences, wherever the participants are from each university and trade, may be thought-about because the outputs of university-industry cooperation. The high variety of non-public contacts additionally indicates the next intensity of collaboration and data transfer between the partners.

Previous studies in the field of collaboration between university and industry identified several factors, Table 1 shows a summary of the factors mentioned in the previous studies.

Table 1

Indicators university-industry cooperation

\begin{tabular}{ll}
\hline Index & \multicolumn{1}{c}{ INDICATORS UNIVERSITY-INDUSTRY COOPERATION } \\
\hline $\mathrm{C} 1$ & R\&D expenditure \\
$\mathrm{C} 2$ & university's governmental income \\
$\mathrm{C} 3$ & non-government donations \\
$\mathrm{C} 4$ & industry sponsorship of university research \\
$\mathrm{C} 5$ & scholarships number of researchers \\
$\mathrm{C} 6$ & number of publications \\
$\mathrm{C} 7$ & projects \\
$\mathrm{C} 8$ & reports or patents done in the past \\
\hline
\end{tabular}


Table 1

Indicators university-industry cooperation (Continued)

\begin{tabular}{cl}
\hline Index & INDICATORS UNIVERSITY-INDUSTRY COOPERATION \\
\hline C9 & number of industry contracts in the university \\
C10 & number of strategies concerning industry-university cooperation in the university \\
C12 & amount of resources dedicated to support cooperation in university \\
C13 & quality certificates (ISO) \\
C14 & previous collaboration with academia \\
C15 & membership of some association or research group \\
C16 & number of scientists \\
C17 & structure of employees by occupation and education \\
C18 & number of previous contracts with universities \\
C19 & involvement with university (e.g. alumni, lecturer) \\
C20 & perception of the firm about the benefits from the cooperation with university \\
\hline Source: compiled by authors based on Barnes et al. (2002), Bercovitz and Feldman (2008), Perkmann et al. (2011), Langford et al. (2006), \\
Iqbal et al. (2011), Tijssen et al. (2009), Luoma et al. (2011).
\end{tabular}

\section{Methodology}

The present research is in terms of purpose, fundamental- practical method and in terms of method of data and information, collection is descriptive-survey. The present research was conducted in the first step using the Fuzzy Delphi method and based on opinions of 38 experts. The method of best worst method was conducted. This section explains this Steps.

\subsection{Fuzzy Delphi Method}

Kaufmann and Gupta were the primary to introduce Fuzzy Delphi Method (FDM) in 1988. The method has been applied quite frequently with success in numerous applications such as; business web site content personal presentation (Kardaras et al., 2013), dry bulk freight predictions (Duru et al., 2012), constructing road safety performance indicators (Ma et al., 2011), etc. Usually, the analysis involves unsure and general datasets, wherever the expert's opinions are usually subjective. Thus, the triangular fuzzy numbers (TFNs) are acceptable to utilize compared with the crisp numbers within the sense that it will represent the knowledge more precisely in real state of affairs. The strategy truly may be a generalization of classical methodology referred to as the urban center method that was developed by Dalkey and Helmer (1963). However, during this paper, we have a tendency to modify the FDM with following extra tools/instruments:

i) Provide the decision matrix to suit with the nature of the datasets,

ii) Utilize the TFNs to evaluate the importance of each attribute,

iii) Equip the decision analysis with 3 levels of confidence using linguistic variables (i.e., Very Optimistic (VO), Neutral (N), and Very Pessimistic (VP)) (see sub-section 3.3)

To evaluate each attribute, in this study, we utilized 7 linguistic variables to represent the level of importance given in Table 2.

Table 2

The seven linguistic variables

\begin{tabular}{ll}
\hline Linguistic variables & TFNs \\
\hline Very low (VL) & $(0,0.1,0.2)$ \\
Low (L) & $(0.1,0.2,0.3)$ \\
Medium low (ML) & $(0.2,0.3,0.4)$ \\
Medlum (M) & $(0.3,0.4,0.7)$ \\
Medium high (MH) & $(0.6,0.7,0.8)$ \\
High (H) & $(0.7,0.8,0.9)$ \\
Very high (VH) & $(0.8,0.9,1.0)$ \\
\hline
\end{tabular}




\subsection{Levels of Confidence based on Linguistic Variables}

In this study the alpha $(\alpha)$-cuts methodology was used for the analysis to discover the influence of the choice variations of the results. The $\alpha$-cut defines the amount of confidence forecast that ends up in the distinction in call results. Thus, we've made the linguistic variables to represent the 3 distinctions assured things as Table 3.

\section{Table 3}

Linguistic expressions of three levels of confidence

\begin{tabular}{ll}
\hline Linguistic variables & TFNs derived from $\left(a_{1}, a_{2}, a_{3}\right)$ \\
\hline Very optimistic (VO) & $\left(a_{1},\left(a_{2}+3 a_{3}\right) / 4, a_{3}\right)$ \\
Neutral $(\mathrm{N})$ & $\left(a_{1}, a_{2}, a_{3}\right)$ \\
Very pessimistic (VP) & $\left(a_{1},\left(a_{2}+3 a_{1}\right) / 4, a_{3}\right)$ \\
\hline
\end{tabular}

To measure the three completely different levels of confidence, we have a tendency to utilize them by some expressions. Then, the three levels of confidence are projected to include with linguistic variables. The score matrix at $\alpha$-level $\left(\widetilde{C L}_{\alpha}\right)$ is given as:

$$
\left(\widetilde{C L}_{\alpha}\right)=\left[\tilde{a}_{i j}\right]_{\alpha}
$$

where $\left.\tilde{a}_{i j}\right|_{\alpha}$ is the triangular fuzzy number derived from $\tilde{a}_{i j}^{r}$ under three different linguistic variables, respectively (i.e., $\mathrm{VO} \approx \alpha=0.80, \mathrm{~N} \approx \alpha=0.50$ and $\mathrm{VP} \approx \alpha=0.20$ ) by Eq. (1). Then, the defuzzification process (Chen, 1996) was performed to derive the crisp values using Eq. (2) given us

$$
\delta / x=\frac{1}{4}\left[\left(a_{1}+2 a_{2}+a_{3}\right)\right]
$$

Next, from crisp values on top, we will rank them in descending order to spot the preferences of every various. Obviously, we will write like $A_{1} \approx A_{2}>\cdots,>A_{n}$ where both symbols ' $\approx$ ' and '>' mean 'is equal to' and 'superior to', respectively.

Thus, the summary of the step-by-step proposed methodology is depicted in Fig. 1.

S1: Categorize the identified datasets and construct the
decision matrix to evaluate each criterion and sub-criterion
based on experts' perspective
S2: Calculate fuzzy average which represents consensus
adjustment and re-examine for verification (if necessary)
S3: Defuzzify an average fuzzy set $\delta / x=\frac{1}{4}\left[a_{1}+2 a_{2}+a_{3}\right]$
S4: Measure the confidence levels of results using linguistic
variables (i.e. $V O, N, V P$ )
S5: Rank them in descending order

Fig. 1. The step-by-step methodology

\subsection{Best-Worst Method}

Best worst methodology is the latest multi-criteria deciding methodology introduced by Rezaei (2015). The premise of this method is to weigh the factors by pairwise comparison like analytic hierarchy method (AHP) and analytic network method (ANP) strategies (Saaty, 2004). BWM has two obvious benefits compared with AHP and ANP methods: initial, less pairwise comparison and second higher consistency magnitude relation. In BWM, by determinative preference of the simplest criterion over different criteria and preference of all criteria on worst criterion by assignment a scale between one and nine, the weights of criteria are fixed. The steps of the BWM are as follows (Rzaei, 2015; Rezaei, 2016): 
1. Determine a set of criteria as $\left\{\mathrm{c}_{1}, \mathrm{c}_{2}, \ldots, \mathrm{c}_{\mathrm{n}}\right\}$

2. Determine the best and the worst criterion by an expert or an experts team

3. Determine the preference vector of best criterion over all criteria by using numbers between 1 and 9 as: $\mathrm{A}_{\mathrm{B}}=\left(a_{\mathrm{B} 1}, a_{\mathrm{B} 2}, \ldots, a_{\mathrm{Bn}}\right)$. Note that $a_{\mathrm{BB}}=1$.

4. Determine the preference vector of all criteria over worst criterion by using numbers between 1 and 9 as: $\mathrm{A}_{\mathrm{W}}=\left(a_{1 \mathrm{~W}}, a_{2 \mathrm{~W}}, \ldots, a_{3 \mathrm{~W}}\right)^{\mathrm{T}}$. Note that $a_{\mathrm{WW}}=1$.

5 . Find the optimal weights $\left(\mathrm{w}_{1}^{*}, \mathrm{w}_{2}^{*}, \ldots, \mathrm{w}_{\mathrm{n}}^{*}\right)$

If the preferences are $a_{\mathrm{Bi}}$ and $a_{\mathrm{iW}}$, the goal is to find the optimal weights which minimize the absolute maximum difference of the $\left.\right|^{\mathrm{w}_{\mathrm{B}}} / \mathrm{w}_{\mathrm{i}}-a_{\mathrm{Bi}} \mid$ and $\left|\mathrm{w}_{\mathrm{i}} / \mathrm{w}_{\mathrm{W}}-a_{\mathrm{iW}}\right|$. By assuming sum of weights equal to one and non-negativity constraints, Rezaei (2016) introduced the linear BWM as follows:

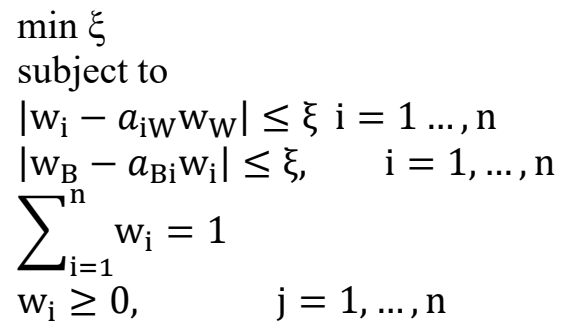

In this paper, linear BWM given in Eqs. (3) is applied to estimate the criteria weights. In the last stage, it is needed to calculate the consistency ratio. Consistency ratio is employed to check how consistent a pairwise reference comparison is. There is full consistency in pairwise comparison vector while $a_{\mathrm{Bj}} \times$ $a_{\mathrm{jW}}=a_{\mathrm{BW}}$. In case which $a_{\mathrm{Bj}} \times a_{\mathrm{jW}} \neq a_{\mathrm{BW}}$, inconsistency occurs. In order to calculate consistency ratio using $\xi$, the corresponding consistency index is considered as follows:

$$
\text { Consistency Ratio }=\frac{\xi}{\text { Consistency Index }}
$$

Consistency values for different $a_{\mathrm{BW}}$ values are presented in a table. For more details readers can refer to Rezaei (2015).

\section{Results}

\subsection{Fuzzy Delphi}

In this stage, the FDM is applied to select the most important practices from the ones listed in the previous stage. The output of FDM is presented in Table 4.

\section{Table 4}

Outputs of fuzzy Delphi method

\begin{tabular}{|c|c|c|c|c|c|c|}
\hline $\mathbf{N}$ & practices & 1 & $\mathbf{m}$ & $\mathbf{u}$ & Defuzzified & Decision \\
\hline 1 & R\&D expenditure & 0.5 & 0.908 & 1 & 0.636 & accept \\
\hline 2 & university's governmental income & 0.25 & 0.721 & 1 & 0.657 & accept \\
\hline 3 & non-government donations & 0.25 & 0.75 & 1 & 0.666 & accept \\
\hline 4 & membership of some association or research group & 0.25 & 0.721 & 1 & 0.657 & accept \\
\hline 5 & scholarships number of researchers & 0.5 & 0.908 & 1 & 0.802 & accept \\
\hline 6 & number of publications & 0 & 0.314 & 0.5 & 0.271 & reject \\
\hline 7 & number of industry contracts at the university & 0.25 & 0.629 & 1 & 0.626 & reject \\
\hline 8 & reports or patents done in the past & 0 & 0.825 & 1 & 0.608 & reject \\
\hline 9 & projects & 0.5 & 0.908 & 1 & 0.802 & accept \\
\hline 10 & number of strategies concerning industry-university cooperation at the university & 0 & 0360 & 0.75 & 0.370 & reject \\
\hline 11 & number of previous contracts with universities & 0.25 & 0.572 & 0.75 & 0.524 & reject \\
\hline 12 & perception of researcher about the benefits from the cooperation with industry & 0.25 & 0.721 & 1 & 0657 & accept \\
\hline 13 & perception of the firm about the benefits from the cooperation with university & 0.5 & 0.825 & 1 & 0.775 & accept \\
\hline 14 & previous collaboration with academia & 0 & 0.572 & 1 & 0.524 & reject \\
\hline 15 & industry sponsorship of university research & 0.25 & 0.655 & 1 & 0.635 & accept \\
\hline 16 & number of scientists & 0 & 0.360 & 0.75 & 0.370 & reject \\
\hline 17 & structure of employees by occupation and education & 0.25 & 0.572 & 0.75 & 0.524 & reject \\
\hline 18 & amount of resources dedicated to support cooperation in university & 0.5 & 0.825 & 1 & 0.775 & accept \\
\hline 19 & involvement with university (e.g. alumni, lecturer) & 0.5 & 0.75 & 1 & 0.75 & accept \\
\hline 20 & quality certificates (ISO) & 0.75 & 1 & 1 & 0.916 & accept \\
\hline
\end{tabular}


According to the experts, the indicators university-industry cooperation was accomplished using the Fuzzy Delphi model. In accordance with Table 5, 20 actions have been taken to promote 12 indictors.

Table 5

Accepted the indicators university-industry cooperation

\begin{tabular}{ll}
\hline indicator & university-industry cooperation \\
\hline C1 & R\&D expenditure \\
C2 & university's governmental income \\
C3 & non-government donations \\
C4 & membership of some association or research group \\
C5 & scholarships number of researchers \\
C6 & projects \\
C7 & perception of researcher about the benefits from the cooperation with industry \\
C8 & perception of the firm about the benefits from the cooperation with university \\
C9 & industry sponsorship of university research \\
C10 & amount of resources dedicated to support cooperation in university \\
C11 & involvement with university (e.g. alumni, lecturer) \\
C12 & quality certificates (ISO) \\
\hline
\end{tabular}

\subsection{Best-worth method}

In accordance with the steps of the BWM described above, in the first step, the experts were asked to choose the best and the worst among the indicators (Table 6). After this step, the preference of each criterion is determined in the best and worst matrix (Table 7 and Table 8), followed by the formulation and final weight of the indicators (Table 9).

Table 6

Best and Worst identified by experts

\begin{tabular}{ccc}
\hline university-industry cooperation & Determined as Best by experts & Determined as worth by experts \\
\hline C1 & 2 & \\
C2 & 4 & $1,2,4,5,7$ \\
C3 & & 3 \\
C4 & 7 & 6 \\
C5 & & \\
C6 & & \\
C7 & $1,3,5,6$ & \\
C8 & & \\
C9 & & \\
C10 & & \\
C11 & & \\
C12 & & \\
\hline
\end{tabular}

As shown in Table 5, the indicator industry sponsorship of university research (C9) is selected as the most important indicator and indicator membership of some association or research group (C4) is selected as the least important indicator.

Table 7

Average comparison of experts in the best indicator

\begin{tabular}{lllllllllllll}
\hline & C1 & C2 & C3 & C4 & C5 & C6 & C7 & C8 & C9 & C10 & C11 & C12 \\
\hline Best indictor(C9) & 2.8 & 4.7 & 5.1 & 6.6 & 6.1 & 2.2 & 4.6 & 3.7 & 1 & 3.3 & 4.9 & 4.3 \\
\hline
\end{tabular}

Table 8

Average comparison of experts in the worth indicator

\begin{tabular}{lllllllllllll}
\hline & $\mathrm{C} 1$ & $\mathrm{C} 2$ & $\mathrm{C} 3$ & $\mathrm{C} 4$ & $\mathrm{C} 5$ & $\mathrm{C} 6$ & $\mathrm{C} 7$ & $\mathrm{C} 8$ & $\mathrm{C} 9$ & $\mathrm{C} 10$ & C11 & C12 \\
\hline Worst indictor(C4) & 5.1 & 5.7 & 4.2 & 1 & 3.5 & 5.1 & 2.4 & 5.9 & 6.6 & 4.4 & 3.4 & 5.7 \\
\hline
\end{tabular}


Table 9

indictor prioritize

\begin{tabular}{lllllllllllll}
\hline & $\mathrm{C} 1$ & $\mathrm{C} 2$ & $\mathrm{C} 3$ & $\mathrm{C} 4$ & $\mathrm{C} 5$ & $\mathrm{C} 6$ & $\mathrm{C} 7$ & $\mathrm{C} 8$ & $\mathrm{C} 9$ & C10 & C11 & C12 \\
\hline Final weight & 0.052 & 0.46 & 0.062 & 0.074 & 0.075 & 0.051 & 0.1 & 0.044 & 0.3 & 0.059 & 0.077 & 0.047 \\
Rank & 8 & 11 & 6 & 5 & 4 & 9 & 2 & 12 & 1 & 7 & 3 & 10 \\
\hline
\end{tabular}

The final ranking of the university-industry cooperation is as follows:

$$
\mathrm{C} 9>\mathrm{C} 7>\mathrm{C} 11>\mathrm{C} 5>\mathrm{C} 4>\mathrm{C} 3>\mathrm{C} 10>\mathrm{C} 1>\mathrm{C} 6>\mathrm{C} 12>\mathrm{C} 2>\mathrm{C} 8
$$

\section{Conclusion and Discussion}

In this study, the Fuzzy Delphi method and BWM were used to identify and prioritize factors affecting the improvement of communication between industry and university. Accordingly, the following actions are recommended to improve this relationship. First, there is a need for the establishment of joint research centers of the university and industry. It is also necessary for the creation of intermediary firms from the government and the development of the fields of study needed by the industry at the universities. It is also recommended to create the necessary conditions for conducting study opportunities for professors in the country's industries to improve this relationship.

Industries can also express their needs and desires in designing industrial designs and in need of research at universities, and to provide material and spiritual support to related university projects. On the other hand, universities can also focus their research and development efforts on the needs of industries in order to ensure that industry satisfies their needs for academic design and research, and universities are also conducting executive and operationalize their research projects.

Increasing the relationship between industry and academia by applying academic research and industry support will help the cooperation between two units. The regular operation of the university authorities, in addition to helping the country's industrial development, also provide public safety. In Iran, after the arrival of the university and the creation of new industries, the concern of the relationship between the two institutions has always been discussed and, after the revolution of 1979, and especially in recent years, many steps have been taken to promote such a relationship.

The experience of different countries suggests that the establishment and deepening of relationships between industry and the university is an important factor in their social, cultural and economic development. Unfortunately, industry owners are not interested in communicating with the university and enjoying their knowledge, and academics also do not have a clear picture of industrial work. This is despite the fact that the university as the most important element of the educational system of the country can play an important role for the development of science and industry. There is a huge potential for universities that this capacity should be effective in interacting with the industry.

In the developed countries, communication and cooperation between industry and the university has a strong backing. In these countries, most industrial developments have started from universities and research centers, and universities are the pioneer of industrial development, while in developing countries, this relationship is weak and negligible. When there is a weak relationship between industry and the university, the technological development is slowly taking place and ultimately leads to a lack of poor performing industry, industry dependency, loss of social capital, etc. The lack of communication between the industry and the university leads to many social and economic challenges, including the problem of unemployment. In Iran, since the formation of industries, there has been some kind of neglect and even the pessimism among industries and universities. Industry owners are not interested in communicating between universities and using their knowledge and science, and on the other hand, academics and students do not have a clear picture of the owners of industrial and industrial work in their minds, and these issues altogether create a difficult cooperation. 


\section{References}

Agrawal, A. K. (2001). University-to-industry knowledge transfer: Literature review and unanswered questions. International Journal of Management Reviews, 3(4), 285-302.

Amabile, T. M., Patterson, C., Mueller, J., Wojcik, T., Odomirok, P. W., Marsh, M., \& Kramer, S. J. (2001). Academic-practitioner collaboration in management research: A case of cross-profession collaboration. Academy of Management Journal, 44(2), 418-431.

Baba, Y., Shichijo, N., \& Sedita, S. R. (2009). How do collaborations with universities affect firms' innovative performance? The role of "Pasteur scientists" in the advanced materials field. Research Policy, 38(5), 756-764.

Bäck, I., \& Kohtamäki, M. (2015). Boundaries of R\&D collaboration. Technovation, 45, 15-28.

Barnes, T., Pashby, I., \& Gibbons, A. (2002). Effective university-industry interaction:: A multi-case evaluation of collaborative r\&d projects. European Management Journal, 20(3), 272-285.

Bedwell, W. L., Wildman, J. L., DiazGranados, D., Salazar, M., Kramer, W. S., \& Salas, E. (2012). Collaboration at work: An integrative multilevel conceptualization. Human Resource Management Review, 22(2), 128-145.

Bercovitz, J., \& Feldman, M. (2008). Academic entrepreneurs: Organizational change at the individual level. Organization Science, 19(1), 69-89.

Brockliss, L. (2000). Gown and town: The university and the city in Europe, 12002000. Minerva, 38(2), 147-170.

Charles, D. (2003). Universities and territorial development: reshaping the regional role of UK universities. Local Economy, 18(1), 7-20.

Cohen, W. M., \& Levinthal, D. A. (1990). Absorptive capacity: A new perspective on learning and innovation. Administrative Science Quarterly, 35(1), 128-152.

Dalkey, N., \& Helmer, O. (1963). An experimental application of the Delphi method to the use of experts. Management Science, 9(3), 458-467.

D'Este, P., \& Patel, P. (2007). University-industry linkages in the UK: What are the factors underlying the variety of interactions with industry?. Research Policy, 36(9), 1295-1313.

Duru, O., Bulut, E., \& Yoshida, S. (2012). A fuzzy extended DELPHI method for adjustment of statistical time series prediction: An empirical study on dry bulk freight market case. Expert Systems with Applications, 39(1), 840-848.

Etzkowitz, H. (2001). The second academic revolution and the rise of entrepreneurial science. IEEE Technology and Society Magazine, 20(2), 18-29.

Etzkowitz, H., Webster, A., Gebhardt, C., \& Terra, B. R. C. (2000). The future of the university and the university of the future: evolution of ivory tower to entrepreneurial paradigm. Research Policy, 29(2), 313-330.

Eun, J. H., Lee, K., \& Wu, G. (2006). Explaining the "University-run enterprises" in China: A theoretical framework for university-industry relationship in developing countries and its application to China. Research Policy, 35(9), 1329-1346.

Franklin, S. J., Wright, M., \& Lockett, A. (2001). Academic and surrogate entrepreneurs in university spin-out companies. The Journal of Technology Transfer, 26(1-2), 127-141.

Giuliani, E., \& Arza, V. (2009). What drives the formation of 'valuable'university-industry linkages?: Insights from the wine industry. Research policy, 38(6), 906-921..

Iqbal, A. M., Khan, A. S., Iqbal, S., \& Senin, A. A. (2011). Designing of success criteria-based evaluation model for assessing the research collaboration between university and industry. International Journal of Business Research and Management, 2(2), 59-73.

Kardaras, D. K., Karakostas, B., \& Mamakou, X. J. (2013). Content presentation personalisation and media adaptation in tourism web sites using Fuzzy Delphi Method and Fuzzy Cognitive Maps. Expert Systems with Applications, 40(6), 2331-2342.

Kaufmann, A., \& Gupta, M. M. (1988). Fuzzy mathematical models in engineering and management science. Elsevier Science Inc. 
Langford, C. H., Hall, J., Josty, P., Matos, S., \& Jacobson, A. (2006). Indicators and outcomes of Canadian university research: Proxies becoming goals?. Research policy, 35(10), 1586-1598.

Lundberg, J., Tomson, G., Lundkvist, I., Sk? r, J., \& Brommels, M. (2006). Collaboration uncovered: Exploring the adequacy of measuring university-industry collaboration through co-authorship and funding. Scientometrics, 69(3), 575-589.

Luoma, P., Raivio, T., Tommila, P., Lunabba, J., Halme, K., Viljamaa, K., \& Lahtinen, H. (2011). Better results, more value. A framework for Analysing the societal impact of Research and Innovation. Tekes review, 288, 2011.

Ma, Z., Shao, C., Ma, S., \& Ye, Z. (2011). Constructing road safety performance indicators using fuzzy delphi method and grey delphi method. Expert Systems with Applications, 38(3), 1509-1514.

Park, H. W., \& Leydesdorff, L. (2010). Longitudinal trends in networks of university-industrygovernment relations in South Korea: The role of programmatic incentives. Research policy, 39(5), 640-649.

Perkmann, M., Neely, A., \& Walsh, K. (2011). How should firms evaluate success in universityindustry alliances? A performance measurement system. R\&D Management, 41(2), 202-216.

Perkmann, M., Tartari, V., McKelvey, M., Autio, E., Broström, A., D’Este, P., ... \& Krabel, S. (2013). Academic engagement and commercialisation: A review of the literature on university-industry relations. Research policy, 42(2), 423-442.

Rasmussen, E., \& Borch, O. J. (2010). University capabilities in facilitating entrepreneurship: A longitudinal study of spin-off ventures at mid-range universities. Research Policy, 39(5), 602-612.

Rezaei, J. (2015). Best-worst multi-criteria decision-making method. Omega, 53, 49-57.

Rezaei, J. (2016). Best-worst multi-criteria decision-making method: Some properties and a linear model. Omega, 64, 126-130.

Saaty, T. L. (2004). Decision making - the analytic hierarchy and network processes (AHP/ANP). Journal of Systems Science and Systems Engineering, 13(1), 1-35.

Santoro, M. D. (2000). Success breeds success: The linkage between relationship intensity and tangible outcomes in industry-university collaborative ventures. The Journal of High Technology Management Research, 11(2), 255-273.

Santoro, M. D., \& Chakrabarti, A. K. (2002). Firm size and technology centrality in industry-university interactions. Research Policy, 31(7), 1163-1180.

Seppo, M., \& Lilles, A. (2012). Indicators measuring university-industry cooperation. Journal of Instrumentation, 204-225.

Siegel, D. S., Waldman, D., \& Link, A. (2003). Assessing the impact of organizational practices on the relative productivity of university technology transfer offices: an exploratory study. Research Policy, 32(1), 27-48.

Steinmo, M., \& Rasmussen, E. (2016). How firms collaborate with public research organizations: The evolution of proximity dimensions in successful innovation projects. Journal of Business Research, 69(3), 1250-1259.

Tijssen, R. J., Van Leeuwen, T. N., \& Van Wijk, E. (2009). Benchmarking university-industry research cooperation worldwide: performance measurements and indicators based on co-authorship data for the world's largest universities. Research Evaluation, 18(1), 13-24.

Tsasis, P. (2009). The social processes of interorganizational collaboration and conflict in nonprofit organizations. Nonprofit Management and Leadership, 20(1), 5-21.

Tuunainen, J., \& Knuuttila, T. (2009). Intermingling academic and business activities: A new direction for science and universities?. Science, Technology, \& Human Values, 34(6), 684-704.

Venkataraman, S. (1997). The distinctive domain of entrepreneurship research: an editor's perspective. In: Katz, J.A. (Ed.), Advances in Entrepreneurship, Firm Emergence and Growth. JAI Press, Greenwich, CT.

Villani, E., Rasmussen, E., \& Grimaldi, R. (2017). How intermediary organizations facilitate university-industry technology transfer: A proximity approach. Technological Forecasting and Social Change, 114, 86-102. 
118

Vohora, A., Wright, M., \& Lockett, A. (2004). Critical junctures in the development of university hightech spinout companies. Research Policy, 33(1), 147-175.

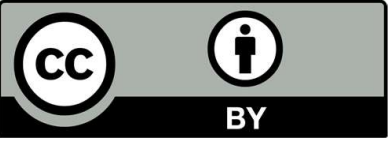

(C) 2019 by the authors; licensee Growing Science, Canada. This is an open access article distributed under the terms and conditions of the Creative Commons Attribution (CC-BY) license (http://creativecommons.org/licenses/by/4.0/). 